\title{
THE OPF AND BUTTERFLY-PSO (BF-PSO) TECHNIQUE BASED OPTIMAL LOCATION AND SIZING OF DISTRIBUTED GENERATION IN MESH SYSTEM
}

\author{
Aashish Kumar Bohre ${ }^{1}$ Dr. Ganga Agnihotri ${ }^{2}$ Dr. Manisha Dubey ${ }^{3}$ \\ Electrical Engineering Department ${ }^{1,2,3}$
}

Maulana Azad National Institute of Technology (MANIT), Bhopal, INDIA ${ }^{1,2,3}$

\begin{abstract}
This paper presents the combined optimal power flow (OPF) and Butterfly-particle swarm optimization (Butterfly-PSO or BF-PSO) techniques to determine the optimal location and sizing of distributed generation (DG). The multi-objective function based on the performance index consider for the multiobjective optimization. The 30-bus mesh system is used for the optimal planning of distributed generation.The comparative result analysis of the proposed methodology and the existing methodology is also reported in this work. The results show that the totalgenerating costand the nodal price are more economical. Also, the reduction in losses (active and reactive power loss) and the improvement in overall performance are efficient.
\end{abstract}

\section{KEYWORDS}

Distributed Generation (DG), Location and Sizing, Optimal Power Flow (OPF), Butterfly-particle swarm optimization (Butterfly-PSO or BF-PSO).

\section{INTRODUCTION}

The distribution system networks areclassified as primary and secondary distribution system.Also, the well known thing about the distribution system network is that, it's built as interconnected meshed networks, but its structure arranges in the radial or tree structure in the operation.There are many researchers have worked on the index basedmulti-objective function to find the optimal location and size of DG such as [1-2].The Butterfly-particle swarm optimization (Butterfly-PSO or BF-PSO) technique based on the butterfly swarm characteristic behavior, intelligence and search process described in [3-4]). The many approaches for optimal allocation and sizing of DG in distribution systemsare introduced by [5-7, 12-13]. The calculation of available transfer capability (ATC) and the shift factors such as the power transfer distribution factors (PTDF) for the transmission system is discussed in [8-9]. The concepts of the power flow and optimal power flow for the system are described by [10-11].

This paper presents the optimal planning of distributed generation (DG) as an active power and reactive power sources, that is as negative PQ load as DG source. Also, proposes the optimal location and sizing of DG based on multi-objective optimization with the different objective indices such as Generation Cost Index (CTI), Active Power Loss Index (PLI), Reactive Power Loss Index (QLI), Voltage Deviation Index (VDI), Load Balancing Index (LBI) and Shift Factor

DOI : 10.14810/elelij.2015.4211 
Electrical and Electronics Engineering: An International Journal (ELELIJ) Vol 4, No 2, May 2015

Index (SFI). The nodal prices of the system also investigated with-DG and without-DG conditions. The optimization results of multi-objective function determined by the ButterflyParticle Swarm Optimization (Butterfly-PSO or BF-PSO) technique.The achieved results showthe overall performance of the system has improved with-DG condition.

\section{THE OPTIMAL POWER FLOW (OPF) AND NODAL PRICING}

\subsection{AC Optimal Power Flow (AC-OPF)}

The optimal power flow (OPF) based on the NR-method to minimize the total generation cost $\mathrm{C}_{\mathrm{f}}$. The totalgeneration cost defined as a second order polynomial generation cost function. The cost function based on the active and reactive power generation cost is:

$$
\begin{aligned}
& \left.\begin{array}{l}
C\left(P_{G}\right)=a+b \times P_{G}+c \times P_{G}^{2} \\
C\left(Q_{G}\right)=a^{\prime}+b^{\prime} \times Q_{G}+c^{\prime} \times Q_{G}{ }^{2}
\end{array}\right\} \\
& C_{f}=\min \sum_{k=1}^{G}\left(C\left(P_{G k}\right)+C\left(Q_{G k}\right)\right)
\end{aligned}
$$

The basic active and reactive power flow equations at $\mathrm{j}^{\text {th }}$ node are given as:

$$
\left.\begin{array}{l}
P_{j}=\sum_{i=1}^{n}\left|V_{j}\right|\left|V_{i}\right|\left|Y_{j i}\right| \cos \left(\theta_{i j}+\delta_{i}-\delta_{j}\right) \\
Q_{j}=-\sum_{i=1}^{n}\left|V_{j}\right|\left|V_{i}\right|\left|Y_{j i}\right| \sin \left(\theta_{i j}+\delta_{i}-\delta_{j}\right)
\end{array}\right\}
$$

With the constraints are:

$$
\left.\begin{array}{l}
\left.\begin{array}{l}
\sum P_{D j}+\sum P_{L j}-P_{D G j}-\sum_{i=1}^{n}\left|V_{j}\right|\left|V_{i}\right|\left|Y_{j i}\right| \cos \left(\theta_{j i}+\delta_{i}-\delta_{j}\right)=0 \\
\sum Q_{D j}+\sum Q_{L j}-Q_{D G j}+\sum_{i=1}^{n}\left|V_{j}\right|\left|V_{i}\right|\left|Y_{j i}\right| \sin \left(\theta_{j i}+\delta_{i}-\delta_{j}\right)=0
\end{array}\right\} \\
\delta_{\text {min }} \leq \delta_{i} \leq \delta_{\max } \\
V_{\text {min }} \leq V_{i} \leq V_{\max } \\
P_{\text {min }} \leq P_{j} \leq P_{\max } \\
Q_{\text {min }} \leq Q_{j} \leq Q_{\max } \\
P_{D G \min } \leq P_{D G j} \leq P_{D G \max } \\
Q_{D G \min } \leq Q_{D G j} \leq Q_{D G \max }
\end{array}\right\}
$$


Where, $P_{j}$ and $Q_{j}$ arethe j-th bus real and reactive power flow. $P_{D j}$ and $Q_{D j}$ the j-th bus real and reactive demand. $V_{i}$ and $V_{j}$ arethe voltage magnitude value at the $i$-thand $j$-th bus. $P_{D G j}$ isthe real power of DG placed atj-th bus. $\delta_{i}, \delta_{j}$ areThe angles of $i$-th and $j$-th bus voltage. $Y_{j i}$ isthe $j i-t h$ element magnitude in bus admittance matrix. $\theta_{j i}$ is the angle of theji-th element in bus admittance matrix. And $\mathrm{n}$ is the total number of buses.

\subsection{Combined Real and Reactive Power for Uniform nodal pricing}

By considering the $\mathrm{j}$-th dispatchable load is modeled as a constant power factor, hence the ratio ofreactive to real demand is a constant.Then the real and reactive power consumption of this load can be thought of as a singlelcombined or bundled commodity. The uniform nodal price value can be expressed on the basis of per MW or per MVAr [11]. Let us assume that the load is located at bus $\mathrm{j}$ and the prices of real and reactive power are $\lambda_{\mathrm{Pj}}$ and $\lambda_{\mathrm{Qj}}$ respectively.So, the combined or bundled power $\chi$ can be given as:

$$
\left.\begin{array}{l}
\chi=\lambda_{P j} P_{D j}+\lambda_{Q j} Q_{D j} \\
\chi=\lambda_{P j} P_{D j}+\lambda_{Q j} \frac{Q_{D j}}{P_{D j}} P_{D j} \\
\chi=\left(\lambda_{P j}+\lambda_{Q j} k_{j}\right) P_{D j}
\end{array}\right\}
$$

Where, $k_{j}=\frac{Q_{D j}}{P_{D j}}=$ constant

In other words the per MW price of the bundled commodity is $\lambda_{\mathrm{Pj}}+\mathrm{k}_{\mathrm{j}} * \lambda_{\mathrm{Qj}}$. Similarly, the per MVAr price is $\lambda_{\mathrm{Pj}} / \mathrm{k}_{\mathrm{j}}+\lambda_{\mathrm{Qj}}$.

\section{THE MULTI-OBJECTIVE PROBLEM FORMULATION AND PERFORMANCE INDICES}

To determine the optimal location and sizing of the distributed generation (DG) in the radial and meshed systemwith the various objectives achieves bythe following multi-objective function $\left(\mathrm{F}_{\mathrm{mo}}\right)$.

$$
F_{M O}=0.12 \times C T I+0.28 \times P U I+0.2 \times Q U+0.16 \times V D I+0.14 \times L B I+0.1 \times S F I
$$

The detail concepts for selecting the weight factor of the indices given in [1, 2]. All these weight factors decide on the basis of the individual impacts and importances of the index while installing the DG.

\subsection{Total Generation Cost Index (CTI)}

The total cost index (CTI) defined by assuming $C T_{D G}$ and $C T_{N o-D G}$ are the total generation cost value with DG and with-out DG of the system. 


$$
C T I=\frac{C T_{D G}}{C T_{N o-D G}}
$$

\subsection{Active Power Loss Index (PLI)}

The active power loss index (PLI) can be expressed byconsidering $P L_{D G}$, and $P L_{N o-D G}$ are the active power losses with DG and with-out DG of the system.

$$
P L I=\frac{P L_{D G}}{P L_{N o-D G}}
$$

\subsection{Reactive Power Loss Index (QLI)}

The reactive power loss index (QLI)givenby considering $Q L_{D G}$, and $Q L_{N o-D G}$ are the reactive power losses with DG and with-out DG of the system.

$$
Q L I=\frac{Q L_{D G}}{Q L_{N o-D G}}
$$

\subsection{Voltage Deviation Index (VDI)}

This voltage deviation index (VDI) given on the basis of the deviation of system voltage from the reference or rated value $\left(\mathrm{V}_{\text {reff }}\right)$. The minimum the voltage deviation index denotes the better the system performance and improvement in voltage profile. This index can be given as:

$$
V D I=\max _{j=2}^{n}\left(\frac{V_{r e f f}-V_{D G j}}{V_{r e f f}}\right)
$$

Where, n-is the total no. of buses.The $V_{\text {reff }}$ and $V_{D G j}$ are the reference voltage and the system voltage value with DG respectively.

\subsection{Load Balancing Index (LBI)}

The load balancing index (LBI) has been given to the concept based on available power at any bus, which is distributed between the loads and next bus. The available power at any bus can be given as:

$$
S_{j}=\sqrt{P_{j}^{2}+Q_{j}^{2}}
$$

Then load balancing index is as:

$$
L B I=\max _{\mathrm{j}=1}^{n-1}\left(\frac{S_{D G j}}{S_{N o-D G j}}\right)
$$


Where, $S_{D G j}$ and $S_{N o-D G j}$ are the available power with DG and with-out DGrespectively, andn is the number of buses.

\subsection{Shift Factor Index (SFI)}

The AC power flow shift factor also called as a power transfer distribution factor (PTDF) is the sensitivity of the power flows. In other words, it indicates the effects of the power flows in all other lines due to the particular power transactions. The relation between PTDF and available transfer capability (ATC) is very close relation, hence the optimum PTDF shows the optimum or maximum ATC with respect to minimum value of $\mathrm{F}_{\mathrm{MO}}$. Let us assume that the change in power due to particular transaction $\Delta t$ is $\Delta x$, then the AC power flow shift factor is:

$$
S F \text { or } P T D F=\frac{\Delta x}{\Delta t}
$$

The installation of DG with particular size will inject some power say $x_{\text {inj }}$ at bus and due to this injection the change in power is $\Delta x$, then shift factor index (SFI) can be given as:

$$
S F I=\max _{\substack{j=1 \\ j \neq \text { slack and } \\ p v b u s}}^{n-1}\left|\frac{\Delta x_{j}}{x_{i n j, j}}\right|
$$

\section{THE BUTTERFLY PARTICLE SWARM BASED OPTIMIZATION (BF-PSO) TECHNIQUES}

The Butterfly-PSO (BF-PSO) algorithm is essentially based on the nectar probability and the sensitivity of the butterfly swarm [3]. The BF-PSO consists of intelligent behavior of the butterfly to find out the optimumamount of nectar. The butterfly particle swarm optimization learning algorithm (BF-PSO) is used to acquire the concept of optimal solutions not only using the random parameters and acceleration parameter, as well as it uses the effect of additional parameter's probability and sensitivity for fast convergence and more accurate optimal solution. In process for computing the optimal solution, the degree of node in every flight of butterfly assumed as approximately equal to 1 because assuming the maximum connectivity in each flight. The butterfly swarm based search process investigates the optimal location depending upon the sensitivity of butterfly toward the flower and the probability of nectar. The information about the optimal solution communicates directly or indirectly between the all butterflies by different means of communication intelligence (such as dancing, colors, chemicals, sounds, physical action and natural processes) [4].

The butterfly leaning based particle swarm optimization algorithm has developed to ascertain the optimal solutions including the random parameters, acceleration coefficients, probability, sensitivity, lbest and gbest. In the Butterfly-PSO, lbest solutions are selected by the individual's best solution. Afterward that the gbest solution identified based on the respective fitness. The locations (location) of the nectar (food) source represent the probable optimal solution for the problem and the amount of nectar (food) represents the corresponding fitness. The detail implementation of the Butterfly-PSO (BF-PSO) technique is given below. The general ranges of 
the sensitivity and probability are considering from 0.0 to 1.0 . The velocity limits can be set based on the limits of the problem variables.Hence, the function of inertia weight, sensitivity and probability as a function of iterations can be given as [3-4]:

$p_{k}=F I T_{g b e s t, k} / \sum\left(F I T_{l b e s t, k}\right)$

$$
\begin{aligned}
& w_{k}=0.9-\left((0.9-0.4) / I T E R_{\max }\right) * I T E R_{k} \\
& s_{k}=\exp -\left(I T E R_{\text {max }}-I T E R_{k}\right) / I T E R_{\text {max }}
\end{aligned}
$$

Where, $I T E R_{\max }=$ maximum number of iterations, and $I T E R_{k}=\mathrm{k}^{\text {th }}$ iteration count.AndFIT $T_{\text {lbest }, k}$ $=$ Fitness of local best solutions with $\mathrm{k}^{\text {th }}$ iteration, $F I T_{\text {gbest, },}=$ Fitness of global best solutions with $\mathrm{k}^{\text {th }}$ iteration.

The Butterfly-PSO (BF-PSO) equations to update the velocity and the position are depends on the sensitivity of the butterfly and the probability of nectar, which can be given as:

$$
v_{k}^{\prime}=w_{k} \cdot v_{k-1}+s_{k}\left(1-p_{k}\right) c_{1} r_{1}\left(x_{\text {lbest }, k-1}-x_{k-1}\right)+p_{k} c_{2} r_{2}\left(x_{g b e s t, k-1}-x_{k-1}\right)
$$

And, the position update equation is:

$$
x_{k}=s_{k} \cdot\left(p_{k} \cdot x_{k-1}+\alpha_{k} \cdot v^{\prime}{ }_{k}\right)
$$

Where, $\alpha_{\mathrm{k}}$ is a varying probability coefficient, $\alpha_{\mathrm{k}}=$ rand ${ }^{*} p_{k}$, rand-is the random number $[0,1]$.The flow chart for the Butterfly-PSO (BF-PSO) technique to find the optimal sizing and location of DG is given in figure-1.

\section{RESULTS AND DISCUSSIONS}

The proposed algorithm is implemented on the 30-bus mesh system [13] with the 100 MVA base.The range of DG size is considered from 0 to 50 for both MW and Mvar. The detail value of generator cost coefficients for mesh system is given in [11]. In this work, the DG is considered to operate on unspecified power factor. The allocation of a DG is considered on the load buses not on the slack bus and voltage-controlled buses in the system. The all results for proposed methodology carried out with MATLAB (2009a)/Matpowe4.1 tool with the system configuration windows-8.1, AMD-E1-1500APU, $1.48 \mathrm{GHz}, 2.0 \mathrm{~GB}$ RAM.

\subsection{The 30-Bus Mesh System}

The all data information about the 30-bus mesh system data have given in reference [13]. The proposed Butterfly-PSO/BF-PSO algorithm applied to minimize the multi-objective function for the 30-bus mesh system. The performance results of the 30-bus mesh system shown in figures from 2 to 9 . The figure- 2 shows the multi-objective function value with their respective index at a particular bus. The value of the DG size, active power loss and active power loss at the all buses is shown in figure-3. The result analysis clearly indicates that the minimum optimal value of the multi-objective function obtain at bus 19 in the 30-bus mesh system. Similarly, the variation of total generation cost and the nodal price of active and reactive power with and without DG respectively given in figure- 4 , figure-5 and figure- 6 . 
Electrical and Electronics Engineering: An International Journal (ELELIJ) Vol 4, No 2, May 2015

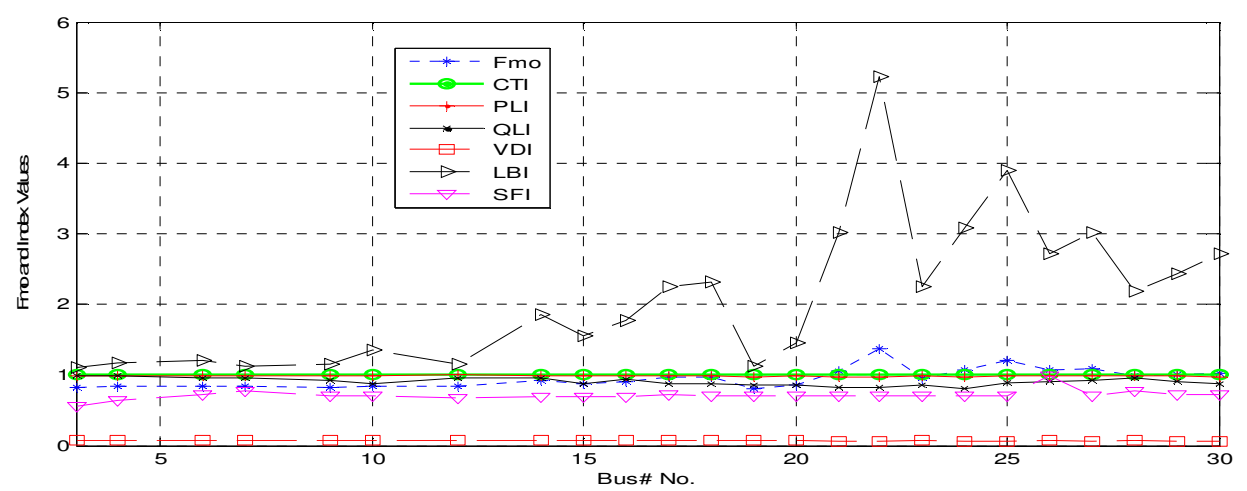

Figure-2: The variation of multi-objective function and various indices at different buses for 30-bus mesh system

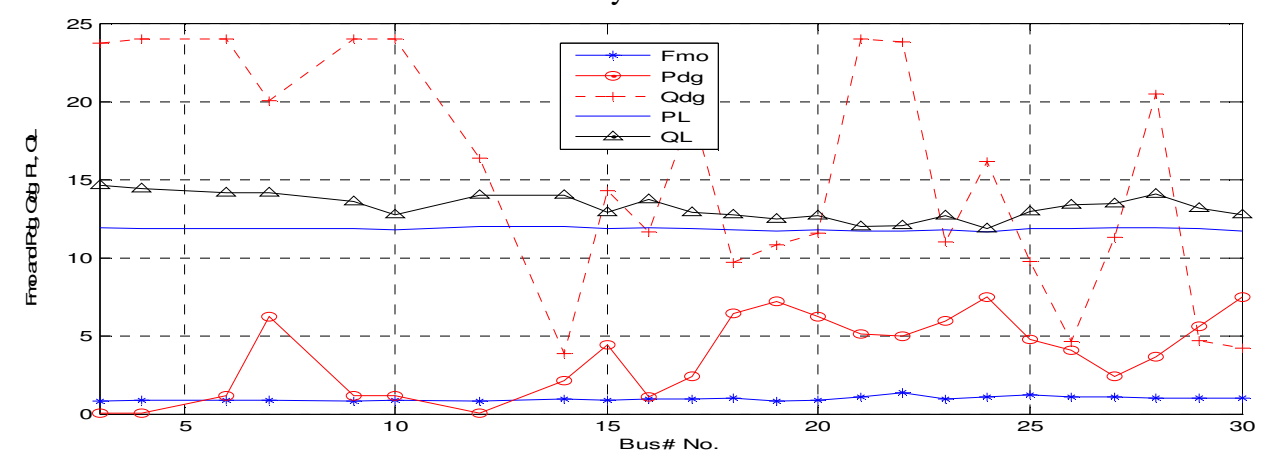

Figure-3: The variation of DG size, and system losses with multi-objective function value of the 30-bus mesh system 
Electrical and Electronics Engineering: An International Journal (ELELIJ) Vol 4, No 2, May 2015

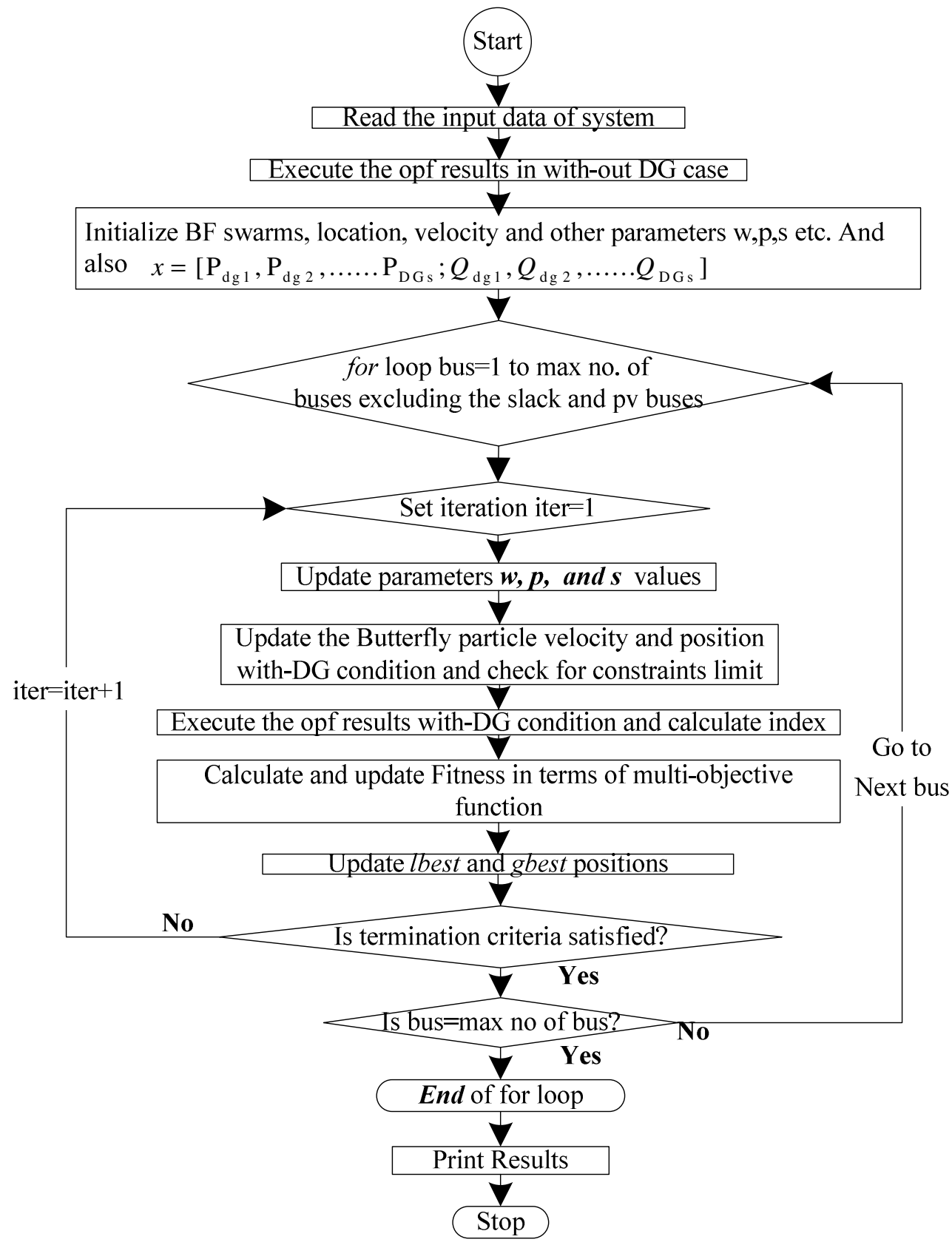

Figure-1: The Butterfly-PSO (BF-PSO) algorithm flow chart

The figure-7 shows the voltage profile with-DG are improved as compared to without-DG condition of the 30-bus mesh system. Similarly, the figure- 8 and figure- 9 shows the performances of the active and reactive power loss with and without-DG. It's analyzed that the losses value with-DG obtain the lower value as compared to without-DG condition. The proposed ButterflyPSO/BF-PSO algorithm gives the optimum value of whole system parameters, which is given in table-1, table-2, and table-3 for the 30-bus mesh system. The comparative analysis of the proposed and existing methodology is shown in table- 4 . The minimal and optimal value of the 
Electrical and Electronics Engineering: An International Journal (ELELIJ) Vol 4, No 2, May 2015

objective function obtains at bus 19, which is the optimal location of DG in the 30-bus mesh system. The corresponding optimal value of their indices is given in the table- 1 by yellow shading row.

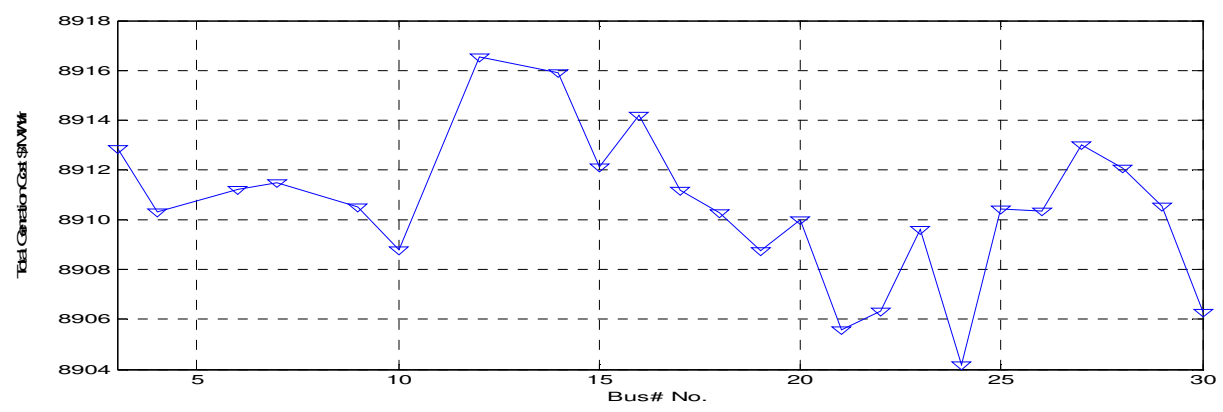

Figure-4: The total generation cost curve at buses for 30-bus mesh system

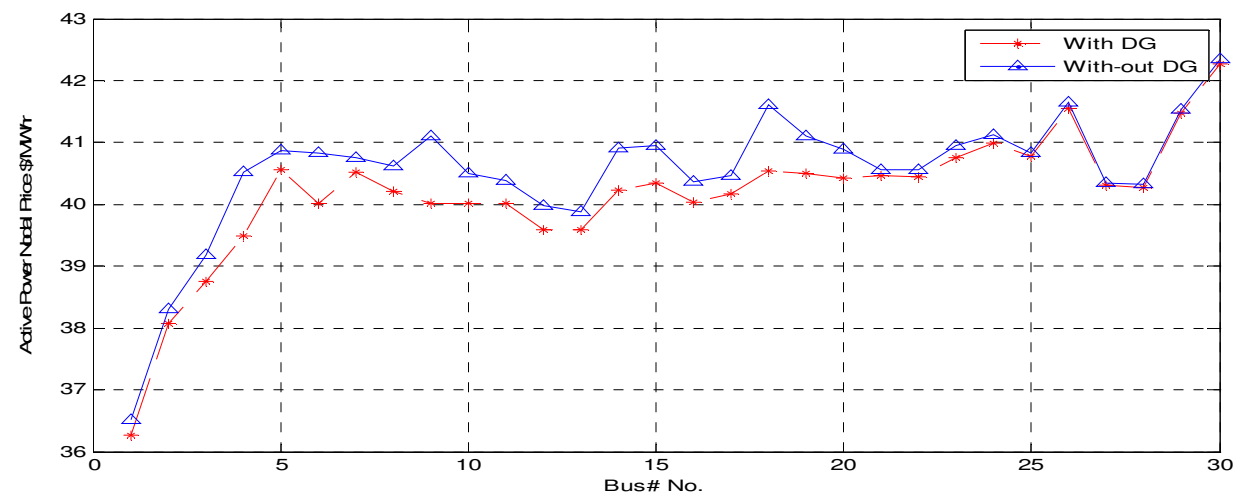

Figure-5: The nodal price of active power with and without DG for 30-bus mesh system

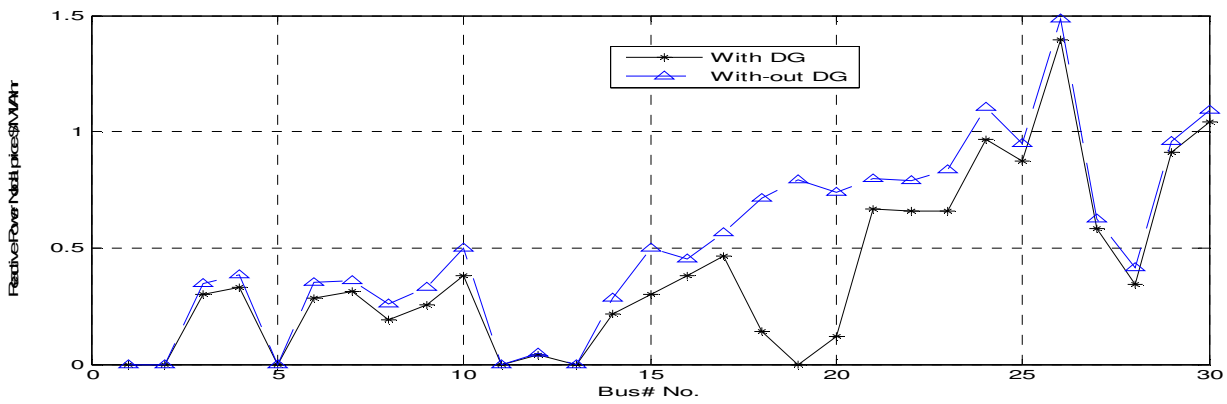

Figure-6: The nodal price of reactive power with and without DG for 30-bus mesh system 
Electrical and Electronics Engineering: An International Journal (ELELIJ) Vol 4, No 2, May 2015

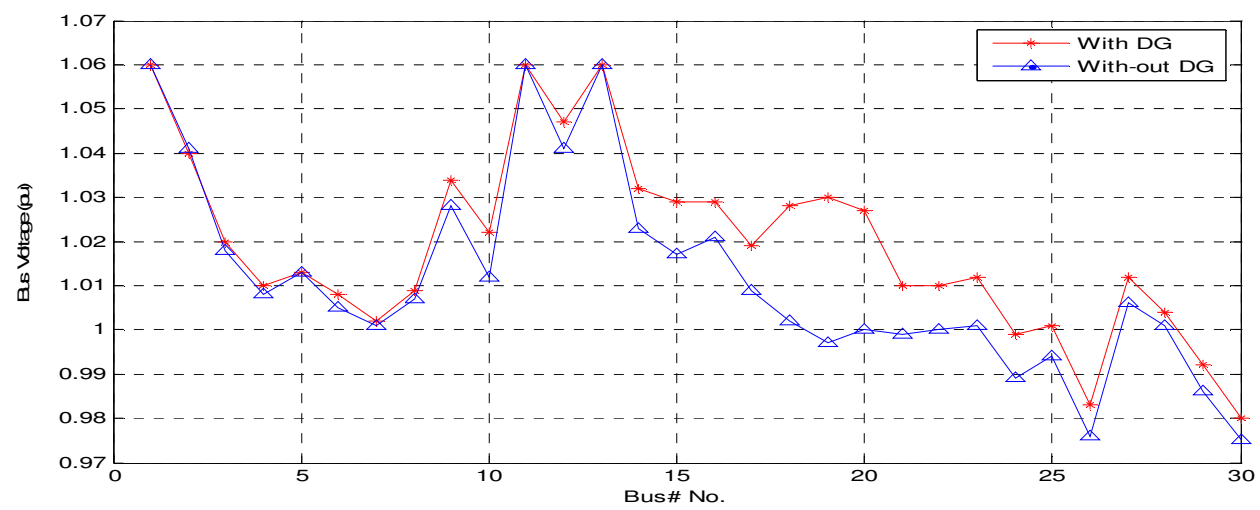

Figure-7: The voltage profile with and without DG for 30-bus mesh system

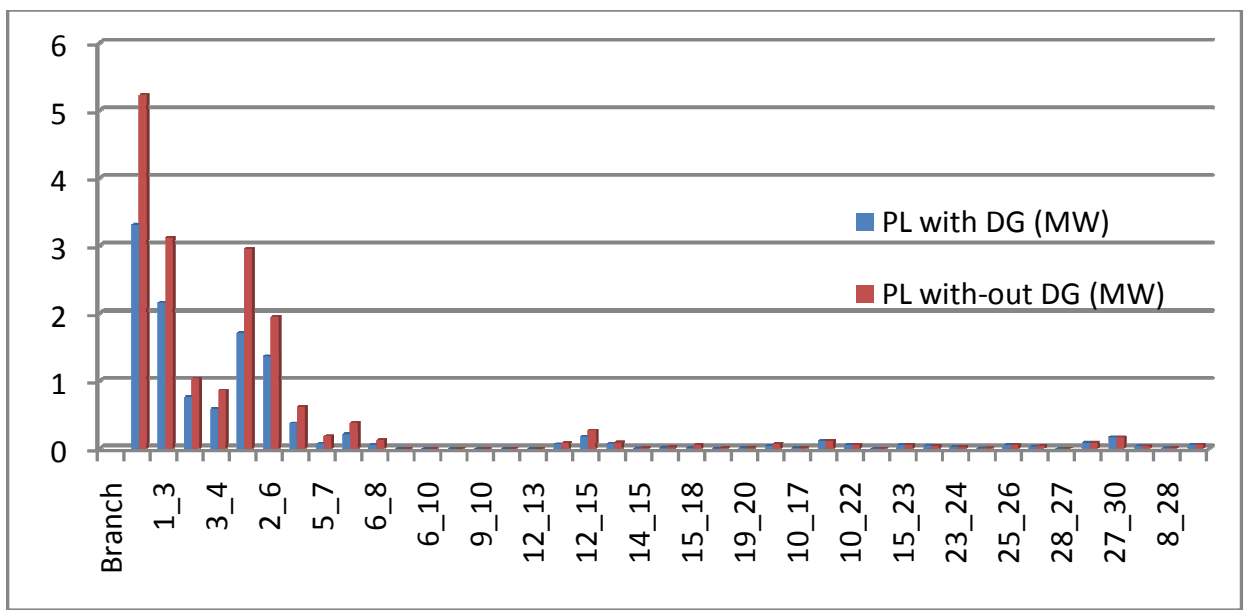

Figure-8: The active power loss with and without DG for 30-bus mesh system

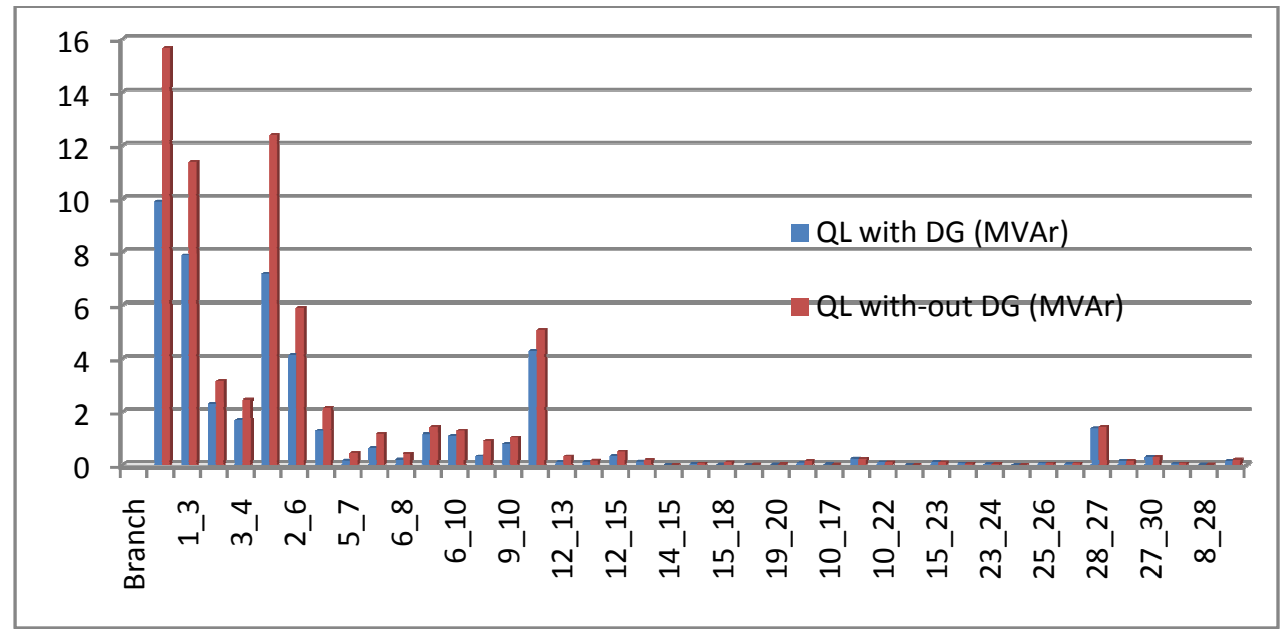

Figure-9: The reactive power loss with and without DG for 30-bus mesh system 
The table-1 shows the global optimal solution results of the Butterfly-PSO/BF-PSO technique based on the respective multi-objective function value and their indices at all the buses excluding the slack and pv busesof 30-bus mesh system. The results indicate that the optimal value of the multi-objective function is 0.802486 at bus-19, which is the better optimal value of fitness in the 30-bus mesh system. The corresponding the optimal value of the multi-objective function, the value of CTI, PLI, QLI VDI, LBI and SFI for the mesh system are 0.999094, 0.978043, 0.848609, $0.075522,1.118642$ and 0.703271 respectively at bus- 19 . Similarly, the table- 6 shows the optimal solution results of the Butterfly-PSO/BF-PSO technique base on the optimal value of the multiobjective function.The active power DG size (PDG), the reactive power DG size (QDG), total generation cost with-out DG (CT-No-DG in $\$ / \mathrm{Mw} / \mathrm{hr}$ ), total generation cost with DG (CT-DG in $\$ / \mathrm{Mw} / \mathrm{hr}$ ), the active power loss with DG (PL-DG) and the reactive power loss with DG (QL-DG) values at bus-19 respectively are 7.175932, 10.83324, 8916.828, 8908.75, 11.73493 and 12.45852 , which are the optimal values corresponding to the multi-objective function value. Theoptimal values of the voltage with and without DG are $1.03 \mathrm{pu}$ and $0.997 \mathrm{pu}$ at bus-19; the active power nodal price with and without DG are 40.502 and $41.107 \$ / \mathrm{Mw} / \mathrm{hr}$; the reactive power nodal price with and without DG are 0 and 0.796 \$/Mvar/hr; all these values given in table- 3 . Also, the comparative results analysis between the proposed and the existing methodology is given in table-4 for the 30-bus mesh system.

Table-1: The value of multi-objective function (Fmo) and indices at buses for 30-bus mesh system

\begin{tabular}{|c|c|c|c|c|c|c|c|c|}
\hline $\begin{array}{c}\text { S. } \\
\text { No. }\end{array}$ & $\begin{array}{c}\text { Obj. } \\
\text { Fun. } \\
\text { Fmo }\end{array}$ & $\begin{array}{c}\text { Bus } \\
\text { No. }\end{array}$ & CTI & PLI & QLI & VDI & LBI & SFI \\
\hline 1 & 0.820262 & 3 & 0.999554 & 0.993607 & 0.99666 & 0.079527 & 1.106511 & 0.551378 \\
\hline 2 & 0.834478 & 4 & 0.999271 & 0.987823 & 0.98372 & 0.078135 & 1.172324 & 0.646037 \\
\hline 3 & 0.841189 & 6 & 0.999372 & 0.989489 & 0.960317 & 0.07302 & 1.205332 & 0.717146 \\
\hline 4 & 0.835114 & 7 & 0.999403 & 0.987307 & 0.963328 & 0.076212 & 1.122472 & 0.767342 \\
\hline 5 & 0.826547 & 9 & 0.999291 & 0.987417 & 0.926524 & 0.072865 & 1.160216 & 0.70762 \\
\hline 6 & 0.840117 & 10 & 0.999097 & 0.983889 & 0.866437 & 0.068951 & 1.358539 & 0.702213 \\
\hline 7 & 0.832264 & 12 & 0.999969 & 0.999719 & 0.951066 & 0.07773 & 1.159534 & 0.673616 \\
\hline 8 & 0.930718 & 14 & 0.999897 & 0.996981 & 0.953892 & 0.079382 & 1.854133 & 0.685175 \\
\hline 9 & 0.870753 & 15 & 0.999472 & 0.987638 & 0.878454 & 0.074684 & 1.554144 & 0.690572 \\
\hline 10 & 0.913721 & 16 & 0.999702 & 0.994497 & 0.933715 & 0.076525 & 1.766786 & 0.689603 \\
\hline 11 & 0.971928 & 17 & 0.999364 & 0.988046 & 0.876999 & 0.071965 & 2.253683 & 0.72922 \\
\hline 12 & 0.973986 & 18 & 0.999266 & 0.981854 & 0.865865 & 0.076224 & 2.313509 & 0.698947 \\
\hline 13 & 0.802486 & 19 & 0.999094 & 0.978043 & 0.848609 & 0.075522 & 1.118642 & 0.703271 \\
\hline 14 & 0.853611 & 20 & 0.999233 & 0.982071 & 0.861859 & 0.07513 & 1.456859 & 0.703698 \\
\hline 15 & 1.059744 & 21 & 0.998741 & 0.974914 & 0.815675 & 0.066104 & 3.017886 & 0.707036 \\
\hline 16 & 1.369632 & 22 & 0.998822 & 0.976576 & 0.819587 & 0.065375 & 5.223495 & 0.706654 \\
\hline 17 & 0.963269 & 23 & 0.999192 & 0.98114 & 0.863189 & 0.072301 & 2.247095 & 0.698471 \\
\hline 18 & 1.065442 & 24 & 0.99858 & 0.968752 & 0.805754 & 0.061476 & 3.089544 & 0.708389 \\
\hline 19 & 1.197512 & 25 & 0.999281 & 0.985004 & 0.882951 & 0.054858 & 3.894946 & 0.711373 \\
\hline 20 & 1.069119 & 26 & 0.999274 & 0.985038 & 0.912041 & 0.067058 & 2.718117 & 0.997219 \\
\hline 21 & 1.083819 & 27 & 0.999572 & 0.992441 & 0.916439 & 0.054376 & 3.019847 & 0.712205 \\
\hline 22 & 0.983066 & 28 & 0.999467 & 0.989966 & 0.959848 & 0.067844 & 2.188022 & 0.767917 \\
\hline 23 & 0.999616 & 29 & 0.999298 & 0.984281 & 0.897857 & 0.06447 & 2.442369 & 0.722833 \\
\hline 24 & 1.028321 & 30 & 0.998816 & 0.97311 & 0.86569 & 0.064107 & 2.719119 & 0.719202 \\
\hline
\end{tabular}


Electrical and Electronics Engineering: An International Journal (ELELIJ) Vol 4, No 2, May 2015

Table-2: The DG size, generation cost and loss values at buses for 30-bus mesh system

\begin{tabular}{|c|c|c|c|c|c|c|}
\hline $\begin{array}{c}\text { Bus } \\
\text { No.1 }\end{array}$ & $\begin{array}{c}\text { PDG } \\
(\mathrm{MW})\end{array}$ & $\begin{array}{c}\text { QDG } \\
(\mathrm{MVAR})\end{array}$ & $\begin{array}{c}\text { CT-No- } \\
\text { DG(\$/M } \\
\text { W/hr })\end{array}$ & $\begin{array}{c}\text { CT-DG } \\
(\$ \mathrm{MW} / \\
\mathrm{hr})\end{array}$ & $\begin{array}{c}\text { PL- } \\
\text { DG(MW }\end{array}$ & $\begin{array}{c}\text { QL-DG } \\
\text { (MVAR) }\end{array}$ \\
\hline 3 & 0.000027 & 23.73224 & 8916.828 & 8912.849 & 11.92167 & 14.63207 \\
\hline 4 & 0.000063 & 23.99985 & 8916.828 & 8910.327 & 11.85228 & 14.44208 \\
\hline 6 & 1.118951 & 23.9995 & 8916.828 & 8911.232 & 11.87227 & 14.0985 \\
\hline 7 & 6.214769 & 20.03782 & 8916.828 & 8911.505 & 11.84609 & 14.14271 \\
\hline 9 & 1.136425 & 23.99928 & 8916.828 & 8910.503 & 11.84741 & 13.60239 \\
\hline 10 & 1.143312 & 23.99912 & 8916.828 & 8908.779 & 11.80507 & 12.72024 \\
\hline 12 & 0.000686 & 16.35806 & 8916.828 & 8916.549 & 11.99501 & 13.9627 \\
\hline 14 & 2.124235 & 3.832528 & 8916.828 & 8915.913 & 11.96216 & 14.00418 \\
\hline 15 & 4.432051 & 14.27119 & 8916.828 & 8912.117 & 11.85006 & 12.89667 \\
\hline 16 & 1.074347 & 11.65781 & 8916.828 & 8914.169 & 11.93235 & 13.70796 \\
\hline 17 & 2.405811 & 19.41585 & 8916.828 & 8911.162 & 11.85495 & 12.87531 \\
\hline 18 & 6.411554 & 9.692087 & 8916.828 & 8910.281 & 11.78065 & 12.71185 \\
\hline 19 & 7.175932 & 10.83324 & 8916.828 & 8908.75 & 11.73493 & 12.45852 \\
\hline 20 & 6.185103 & 11.57075 & 8916.828 & 8909.988 & 11.78326 & 12.65304 \\
\hline 21 & 5.133457 & 23.99148 & 8916.828 & 8905.602 & 11.69739 & 11.975 \\
\hline 22 & 4.949482 & 23.79505 & 8916.828 & 8906.328 & 11.71732 & 12.03244 \\
\hline 23 & 5.912414 & 10.98231 & 8916.828 & 8909.628 & 11.77209 & 12.67256 \\
\hline 24 & 7.486107 & 16.14139 & 8916.828 & 8904.168 & 11.62345 & 11.82935 \\
\hline 25 & 4.751696 & 9.750311 & 8916.828 & 8910.417 & 11.81846 & 12.9627 \\
\hline 26 & 4.09458 & 4.601022 & 8916.828 & 8910.357 & 11.81886 & 13.38977 \\
\hline 27 & 2.370212 & 11.31705 & 8916.828 & 8913.009 & 11.90769 & 13.45434 \\
\hline 28 & 3.626638 & 20.46589 & 8916.828 & 8912.077 & 11.87799 & 14.09162 \\
\hline 29 & 5.569172 & 4.697014 & 8916.828 & 8910.568 & 11.80978 & 13.18153 \\
\hline 30 & 7.483638 & 4.192573 & 8916.828 & 8906.273 & 11.67575 & 12.70929 \\
\hline & & & & & & \\
\hline
\end{tabular}

Table-3: The voltage, active and reactive power nodal price on buses with and without DG for 30-bus mesh system

\begin{tabular}{|c|c|c|c|c|c|c|}
\hline $\begin{array}{c}\text { Bus } \\
\text { No. }\end{array}$ & $\begin{array}{c}\text { Voltage } \\
\text { with-DG }\end{array}$ & $\begin{array}{c}\text { Voltage } \\
\text { No-DG }\end{array}$ & $\begin{array}{c}\text { Nodal } \\
\text { price of P } \\
\text { with-DG }\end{array}$ & $\begin{array}{c}\text { Nodal } \\
\text { price of P } \\
\text { No-DG }\end{array}$ & $\begin{array}{c}\text { Nodal } \\
\text { price of Q } \\
\text { with-DG }\end{array}$ & $\begin{array}{c}\text { Nodal } \\
\text { price of Q } \\
\text { No-DG }\end{array}$ \\
\hline 1 & 1.06 & 1.06 & 36.266 & 36.306 & -0.104 & -0.082 \\
\hline 2 & 1.04 & 1.041 & 38.064 & 38.107 & 0 & 0 \\
\hline 3 & 1.02 & 1.018 & 38.756 & 38.818 & 0.3 & 0.349 \\
\hline 4 & 1.01 & 1.008 & 39.491 & 39.562 & 0.329 & 0.387 \\
\hline 5 & 1.013 & 1.013 & 40.563 & 40.587 & 0 & 0 \\
\hline 6 & 1.008 & 1.005 & 40.023 & 40.083 & 0.283 & 0.351 \\
\hline 7 & 1.002 & 1.001 & 40.525 & 40.575 & 0.315 & 0.359 \\
\hline 8 & 1.009 & 1.007 & 40.217 & 40.262 & 0.192 & 0.26 \\
\hline 9 & 1.034 & 1.028 & 40.022 & 40.096 & 0.256 & 0.33 \\
\hline 10 & 1.022 & 1.012 & 40.024 & 40.11 & 0.382 & 0.501 \\
\hline 11 & 1.06 & 1.06 & 40.021 & 40.093 & 0 & 0 \\
\hline 12 & 1.047 & 1.041 & 39.587 & 39.676 & 0.04 & 0.05 \\
\hline 13 & 1.06 & 1.06 & 39.587 & 39.676 & 0 & 0 \\
\hline 14 & 1.032 & 1.023 & 40.224 & 40.359 & 0.215 & 0.283 \\
\hline 15 & 1.029 & 1.017 & 40.346 & 40.555 & 0.303 & 0.501 \\
\hline 16 & 1.029 & 1.021 & 40.044 & 40.136 & 0.382 & 0.453 \\
\hline
\end{tabular}


Electrical and Electronics Engineering: An International Journal (ELELIJ) Vol 4, No 2, May 2015

\begin{tabular}{|l|c|c|c|c|c|c|}
\hline 17 & 1.019 & 1.009 & 40.179 & 40.271 & 0.465 & 0.568 \\
\hline 18 & 1.028 & 1.002 & 40.543 & 41.006 & 0.141 & 0.716 \\
\hline 19 & 1.03 & 0.997 & 40.502 & 41.107 & 0 & 0.796 \\
\hline 20 & 1.027 & 1 & 40.42 & 40.885 & 0.118 & 0.739 \\
\hline 21 & 1.01 & 0.999 & 40.467 & 40.569 & 0.669 & 0.799 \\
\hline 22 & 1.01 & 1 & 40.45 & 40.553 & 0.658 & 0.788 \\
\hline 23 & 1.012 & 1.001 & 40.763 & 40.946 & 0.661 & 0.837 \\
\hline 24 & 0.999 & 0.989 & 40.98 & 41.114 & 0.968 & 1.107 \\
\hline 25 & 1.001 & 0.994 & 40.764 & 40.84 & 0.873 & 0.952 \\
\hline 26 & 0.983 & 0.976 & 41.549 & 41.64 & 1.397 & 1.487 \\
\hline 27 & 1.012 & 1.006 & 40.314 & 40.353 & 0.585 & 0.627 \\
\hline 28 & 1.004 & 1.001 & 40.267 & 40.328 & 0.343 & 0.416 \\
\hline 29 & 0.992 & 0.986 & 41.472 & 41.527 & 0.911 & 0.957 \\
\hline 30 & 0.98 & 0.975 & 42.275 & 42.342 & 1.044 & 1.093 \\
\hline
\end{tabular}

Table-4: The Comparative analysis of 30-bus radial system

\begin{tabular}{|c|c|c|c|c|c|}
\hline \multirow{2}{*}{\multicolumn{2}{|c|}{$\begin{array}{l}\text { Parameter } \\
\text { Cases } \\
\text { With-out-DG (Base case) }\end{array}$}} & $\begin{array}{c}\text { Active power } \\
\text { loss (MW) }\end{array}$ & $\begin{array}{l}\text { Active power } \\
\text { loss reduction } \\
(\%)\end{array}$ & $\begin{array}{c}\text { Reactive } \\
\text { power loss } \\
\text { (MVAR) }\end{array}$ & $\begin{array}{l}\text { Reactive power } \\
\text { loss reduction } \\
(\%)\end{array}$ \\
\hline & & 17.807 & --- & 69.61 & --- \\
\hline \multirow{2}{*}{$\begin{array}{l}\text { With- } \\
\text { DG (at } \\
\text { bus-19) }\end{array}$} & Existing & $15.3945[13]$ & $13.55 \%$ & NA & NA \\
\hline & $\begin{array}{l}\text { Proposed } \\
\text { PDG(7.175932) } \\
\text { QDG(10.83324) }\end{array}$ & 11.735 & $34.1 \%$ & 47.02 & $32.45 \%$ \\
\hline
\end{tabular}

\section{CONCLUSIONS}

The optimal allocation and sizing of the distributed generation (DG) with multi-objective optimization problembased on the indices using the Butterfly-PSO/BF-PSO optimization technique has been proposed. The results analysis of the 30-bus mesh system clarifies that the proposed method is the efficient method for the reduction of power losses, the improvement of the voltage profile, increase the load balancing capacity hence the maximum loading capacity, the more generation cost economy, the optimal shift factor value hence increases ATC, and reduction in MVA flows and MVA intake from the system or grid. The comparative analysis of the results for the proposed and existing methodology is given in table-4 for 30-bus mesh system. These comparative results analyses of the 30-bus mesh system shows the reduction in active power loss with the existing methodology is $13.55 \%$. And also, the reduction in active and reactive power losses with the proposed methodology is $34.1 \%$ and $32.45 \%$ respectively, which is the more power loss reduction as compared with existing method.

\section{ACKNOWLEDGMENT}

The authors wish to acknowledge the MANIT, Bhopal, and MHRD for financial support. Also, the authors want to extend acknowledge to all members of electrical department of MANITfor supporting directly or indirectly. 


\section{REFERENCES}

[1] Deependra Singh, Devender Singh, and K. S. Verma, "Multiobjective Optimization for DG Planning With Load Models" IEEE Transactions on Power Systems, vol. 24, no. 1, pp. 427-436, February 2009.

[2] A.M. El-Zonkoly, "Optimal placement of multi-distributed generation units including different load models using particle swarm optimization" ELSEVIER, swarm and evolutionary computation, vol.1, pp. 50-59, 2011.

[3] A.K. Bohre, G. Agnihotri, and M. Dubey, "Hybrid butterfly based particle swarm optimization for optimization problems," First International Conference on Networks \& Soft Computing (ICNSC), 2014, pp.172-177, 19-20 Aug. 2014. doi: 10.1109/CNSC.2014.6906650.

[4] A.K. Bohre, G. Agnihotri, M. Dubey, and J. S. Bhadoriya "A novel method to find optimal solution based on modified butterfly particle swarm optimization," International Journal of Soft Computing, Mathematics and Control (IJSCMC), vol. 3, no. 4, pp.1-14, Nov. 2014. doi: 10.14810/ijscmc.2014.3401.

[5] Hasanpour, S., R. Ghazi, and M. H. Javidi. "A new approach for cost allocation and reactive power pricing in a deregulated environment." Electrical Engineering, vol. 91, no. 1, pp. 27-34, 2009.

[6] Canizares, C. A., K. Bhattacharya, I. El-Samahy, H. Haghighat, J. Pan, and C. Tang. "Re-defining the reactive power dispatch problem in the context of competitive electricity markets." Generation, Transmission \& Distribution, IET4, no. 2, pp.162-177, 2010.

[7] Kansal, Satish, Vishal Kumar, and Barjeev Tyagi. "Composite active and reactive power compensation of distribution networks." Industrial and Information Systems (ICIIS-2012), 7th IEEE International Conference on. IEEE, 2012.

[8] Kumar, Ashwani, S. C. Srivastava, and S. N. Singh. "Available Transfer Capability (ATC) determination in a competitive electricity market using AC distribution factors." Electric Power Components and Systems vol.32, no.9,pp. 927-939, 2004.

[9] Kumar, Ashwani, and Jitendra Kumar. "Comparison of UPFC and SEN transformer for ATC enhancement in restructured electricity markets."International Journal of Electrical Power \& Energy Systems vol.41, no.1,pp. 96-104, 2012.

[10] Rashtchi, Vahid, and Saeed Pashai. "Network Reconfiguration in Distribution Power System with Distributed Generators for Power Loss Minimization."International Conference on Advances in Computer and Electrical Engineering (ICACEE-2012), 2012.

[11] Zimmerman, Ray D.,Murillo-Sanchez, Carlos E.. "Matpower4.1" December, 2011.http://www.pserc.cornell.edu//matpower/

[12] Dommel, H.W.; Tinney, W.F., "Optimal Power Flow Solutions," Power Apparatus and Systems, IEEE Transactions on, vol.PAS-87, no.10, pp.1866,1876, Oct. 1968. doi: 10.1109/TPAS.1968.292150

[13] Ugranl1, Faruk, and Engin Karatepe. "Convergence of rule-of-thumb sizing and allocating rules of distributed generation in meshed power networks."Renewable and Sustainable Energy Reviews vol.16, no. 1,pp. 582-590, 2012.

\section{AUTHOR}

Aashish Kumar Bohre ${ }^{1}$ received BE degree in Electrical and Electronics engineering from UIT- RGPV Bhopal, (2009), and M-Tech degree in Power System (2011) from MANIT, Bhopal. At the moment he is Ph.D. scholar at MANIT, Bhopal, India.

Dr. Ganga Agnihotri ${ }^{2}$ received BE degree in Electrical engineering from MACT, Bhopal (1972), the ME degree (1974) and PhD degree (1989) from University of Roorkee, India. Since 1976 she is with Maulana Azad College of Technology, Bhopal in various positions. Currently, she is professor. Her research interest includes Power System Analysis, Power System

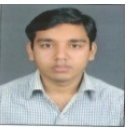
Optimization and Distribution Operation. 
Dr. Manisha Dubey ${ }^{3}$ was born in Jabalpur in India on 15 th December 1968. She received her B.E (Electrical), M.Tech. (Power Systems) and Ph.D (Electrical Engg.) in 1990, 1997 and 2006 respectively. She is working as Professor at the Department of Electrical Engineering, National Institute of Technology, Bhopal, India. Her research interests include power systems, Genetic Algorithms, Fuzzy Logic systems and application of Soft Computing Techniques in power system dynamics and control. 